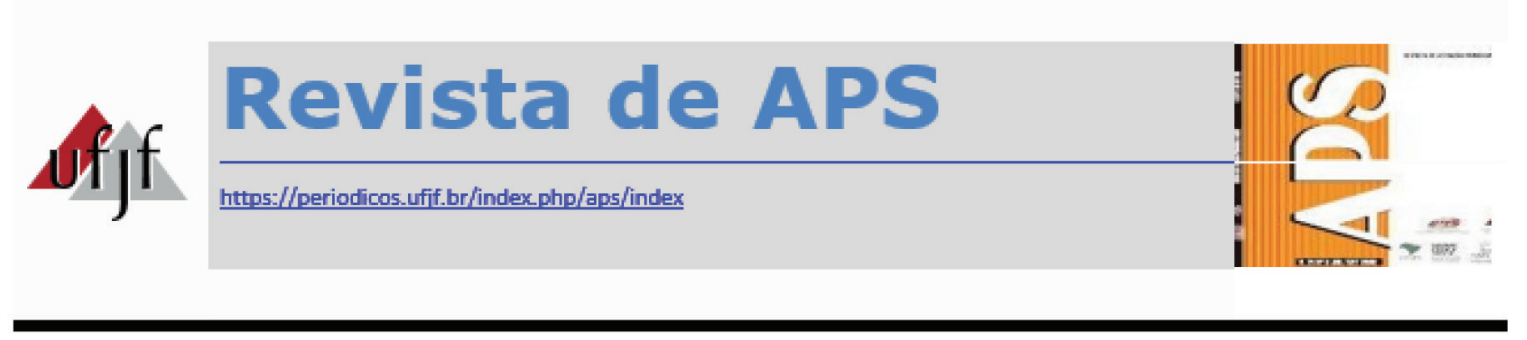

\title{
Avaliação da rotulagem nutricional de biscoitos recheados com apelo infantil
}

\section{Evaluation of the nutritional labeling of cookies with children's appeal}

\author{
Vanessa Sequeira Fontes ${ }^{1}$, Felipe Silva Neves ${ }^{2}$, Jéssica Carolina Assis Feitosa ${ }^{3}$, \\ Mirella Lima Binoti ${ }^{4}$
}

\begin{abstract}
RESUMO
O objetivo do trabalho foi avaliar qualitativa e quantitativamente os rótulos de biscoitos recheados com apelo infantil encontrados em redes de supermercados do município de Juiz de Fora/MG. Foi realizado um estudo transversal que investigou as embalagens de biscoitos recheados destinados ao público infantil, especialmente os rótulos nutricionais, por meio de análises qualitativas - atendimento da presença das informações obrigatórias exigidas nas resoluções - e quantitativas - adequação dos valores de energia, carboidrato, proteína, fibras, sódio, gordura total, saturada e trans em relação ao percentual do valor diário recomendado (\%VDR) da Ingestão Diária Recomendada (IDR) para crianças de 2 a 6 anos de idade. Para a análise estatística foi utilizado o software SPSS ${ }^{\circledR}$ versão 21.0 . Analisaram-se 16 produtos e constatou-se que $100 \%$ da amostra atendeu aos itens obrigatórios que devem estar presentes na rotulagem preconizados pela legislação vigente. Foi observado que a maioria dos produtos ultrapassou o \%VDR para crianças em relação a energia, macronutrientes, sódio e fibras. Os biscoitos recheados analisados apresentam
\end{abstract}

\footnotetext{
${ }^{1}$ Graduada em Fonoaudiologia pelo Centro de Ensino Superior de Juiz de Fora (2007) e em Nutrição pela Universidade Federal de Juiz de Fora (2014). Especialista em Voz pelo Centro de Ensino Superior de Juiz de Fora (2010) e Mestra em Saúde Coletiva pela Universidade Federal de Juiz de Fora. Atualmente é professora substituta do Departamento de Nutrição e integra o Grupo de Pesquisa em Nutrição e Saúde Coletiva (GPENSC) da referida instituição. E-mail: vanessa@solinformaticajf.com.br

${ }^{2}$ Graduado em Nutrição (2014) e mestre em Saúde (2016) pela Universidade Federal de Juiz de Fora (UFJF); especialista em Informática em Saúde (2016) pela Universidade Federal de São Paulo; e especialista em Saúde Pública (2016), com ênfase em Saúde da Família, pelo Centro Universitário Internacional. Cursa doutorado em Saúde Coletiva (2017 - Atual), área de concentração em Epidemiologia, pela Faculdade de Medicina da UFJF. Foi professor substituto do Departamento de Nutrição da UFJF (2014), ao qual mantém-se vinculado como integrante do Grupo de Pesquisa em Nutrição e Saúde Coletiva - G-PENSC (2014 - Atual).

${ }^{3}$ Graduada em Nutrição pela Universidade Federal de Juiz de Fora (UFJF).

${ }^{4}$ Graduada em Nutrição pela Universidade Vila Velha (2003), mestrado em Biologia Vegetal pela Universidade Federal do Espírito Santo (2006) e doutorado em Ciência e Tecnologia de Alimentos pela Universidade Federal de Viçosa (2012). Atualmente é professora adjunta da Universidade Federal de Viçosa. Tem experiência na área de Nutrição, com ênfase em Dietética, Ciência e Tecnologia dos Alimentos e em Gestão de Unidades de Alimentação e Nutrição.
} 
alterações quantitativas na rotulagem nutricional em relação aos valores de referência para a população infantil. Reiteramos a necessidade de mudanças na regulamentação da rotulagem nutricional de forma a facilitar a compreensão dos consumidores e sugerimos estudos complementares.

PALAVRAS-CHAVE: Rotulagem nutricional. Criança. Alimentação escolar

\begin{abstract}
The objective of this study was to evaluate qualitatively and quantitatively the labels of cookies that appeal to children and that are found in supermarket chains in the city of Juiz de Fora/MG. A cross-sectional study was carried out to investigate the package of cookies intended for children, especially nutritional labels, by means of qualitative analyzes - attendance of the mandatory information required in the resolutions - and quantitative - adequacy of energy, carbohydrate and protein values , fiber, sodium, total fat, saturated and trans in relation to the Recommended Daily Intake Percentage (\% VDR) for children from 2 to 6 years of age. Statistical analysis was performed using the SPSS ${ }^{\circledR}$ software version 21.0. A total of 16 products were analyzed and it was verified that $100 \%$ of the sample met the mandatory items that must be present in the labeling recommended by current legislation. Regarding energy, macronutrients, sodium and fiber, it was noted that most products exceeded $\%$ VDR for children. The cookies analyzed present quantitative changes in nutritional labeling in relation to the reference values for the infant population. We reiterate the need for changes in the regulation of nutrition labeling in order to facilitate consumer understanding and we suggest complementary studies.
\end{abstract}

KEYWORDS: Nutritional labeling. Child. School feeding.

\title{
INTRODUÇÃO
}

A prevalência mundial de crianças com excesso ponderal é crescente, especialmente nas últimas décadas, assumindo caráter epidemiológico e tornando-se um dos maiores problemas de saúde pública desse século. Dados referentes ao período de 1980 a 2013 apontam crescimento na prevalência de excesso de peso de 47,1\% para crianças ${ }^{1}$. Tal tendência vem acompanhada pelo crescimento da compra e consumo de alimentos processados e ultraprocessados ${ }^{2}$. Observa-se que no Brasil ocorre esse mesmo panorama, conforme apontam diferentes estudos com essa população ${ }^{3,4}$.

O consumo alimentar infantil está associado a prevalência de excesso de peso e é influenciado por diversos aspectos, dentre esses, se destaca a influência do marketing e das propagandas, encontradas não somente na mídia televisiva e internet, mas também nas embalagens dos produtos destinados a esse público. Crianças expostas a publicidade tornam-se mais vulneráveis aos anúncios de produtos ultraprocessados, de alto valor calórico e baixo valor nutricional ${ }^{5}$.

As embalagens são o primeiro contato do consumidor com o produto, sendo a rotulagem uma das estratégias da Organização Mundial da Saúde (OMS) para orientar o consumidor quanto à qualidade e à quantidade dos componentes nutricionais, colaborando 
na promoção de escolhas alimentares mais saudáveis e prevenindo o desenvolvimento de doenças crônicas não transmissíveis, podendo ainda ser utilizada como importante instrumento para educação alimentar e nutricional. Além disso, o rótulo deve conter informações precisas, claras e confiáveis para que o mesmo possa tomar a sua decisão no momento da compra. A rotulagem dos alimentos é regulamentada por legislação específica, e deve evitar ilusões e falsas alegações que favoreçam uma escolha errônea do produto ${ }^{6}$.

O Guia Alimentar para a População Brasileira ${ }^{7}$ defende a promoção da alimentação saudável com base em alimentos, destacando que a "alimentação é mais que ingestão de nutrientes". No entanto, os rótulos declaram somente sobre nutrientes e suas alegações de saúde igualmente consideram apenas tal aspecto, não valorizando o grau de processamento dos produtos ou a quantidade de corantes e conservantes.

O parâmetro de escolha de alimentos considerados saudáveis pelo consumidor no momento da compra, previsto pela legislação, é a informação nutricional obrigatória e complementar, apresentada nos rótulos numa linguagem tecnicista que contrasta com a criatividade e a liberdade das mensagens publicitárias, que ocupam a maior parte das embalagens e disputam a atenção do público ${ }^{8}$.

O presente estudo tem por objetivo avaliar qualitativa e quantitativamente os rótulos de biscoitos recheados com apelo infantil encontrados em redes de supermercados de uma cidade da zona da mata mineira.

\section{MATERIAIS E MÉTODOS}

\section{Delineamento do estudo}

Trata-se de um estudo observacional do tipo transversal descritivo, que investigou as embalagens de biscoitos recheados destinados ao público infantil, especialmente os rótulos nutricionais, por meio de análises quantitativas e qualitativas.

\section{Seleção dos biscoitos recheados}

Os produtos foram selecionados em três principais redes de supermercados da cidade de Juiz de Fora (MG) durante o mês de março de 2015. Optou-se por eleger os biscoitos recheados conforme a disponibilidade em comum nos três supermercados, identificando produtos de diferentes marcas.

Posteriormente, foi realizada uma segunda seleção que consistiu em identificar os biscoitos recheados que demonstraram algum apelo infantil, aqui incluídos aqueles cujas embalagens apresentaram alegações por escrito ou por meio de ilustrações de animais, personagens infantis, desenhos animados, jogos de passatempo ou aqueles que ofereciam brindes ou frases direcionadas a esse público. 
Foram excluídas as embalagens que não apresentavam informação a respeito do tamanho da porção, assim como aquelas que exibiram tamanho de porção somente por medida caseira.

\section{Análise qualitativa}

Os rótulos dos biscoitos recheados foram analisados qualitativamente quanto ao atendimento da presença das informações obrigatórias exigidas nas resoluções RDC 359/03 - Regulamento Técnico de Porções de Alimentos Embalados para Fins de Rotulagem Nutricional ${ }^{9}$ e RDC 360/03 - Regulamento Técnico sobre Rotulagem Nutricional de Alimentos Embalados ${ }^{8}$. Os itens analisados foram: a) porção (g); b) medida caseira; c) percentual do valor diário de referência (\%VDR); d) valor energético (kcal ou joule); e) carboidrato (g); f) proteína (g); g) gorduras totais (g); h) gordura saturada (g); i) gordura trans (g); j) fibras (g); k) sódio (mg); I) presença da frase: "\% Valores Diários com base em uma dieta de 2.000 kcal ou 8400 kJ. Seus valores diários podem ser maiores ou menores dependendo de suas necessidades energéticas"; m) lista de ingredientes.

Foi avaliada também a categorização dos biscoitos, quanto à definição em um dos grupos identificados pela regulamentação brasileira e do Mercosul ${ }^{9}$. A saber: (a) produtos de panificação, cereais, leguminosas, raízes e tubérculos, e seus derivados; (b) verduras, hortaliças e conservas vegetais; (c) frutas, sucos, néctares e refrescos de frutas; (d) leite e derivados; (e) carnes e ovos; (f) óleos, gorduras e sementes oleaginosas; (g) açúcares e produtos com energia proveniente de carboidratos e gorduras; (h) molhos, temperos prontos, caldos, sopas e pratos preparados.

\section{Análise quantitativa}

Os dados de energia, carboidrato, proteína, fibras, sódio, gordura total, saturada e trans obtidos dos rótulos dos produtos na etapa qualitativa foram analisados quanto a sua adequação quantitativa em relação ao \%VDR da Ingestão Diária Recomendada (IDR) para crianças de 2 a 6 anos de idade.

No que se refere ao estabelecimento do valor diário de referência (VDR) foram utilizados valores médios de recomendação de nutrientes para a faixa etária de 2 a 6 anos de idade, segundo Institute of Medicine ${ }^{10}$ e para a necessidade calórica diária total média preconizou-se $1.300 \mathrm{kcal} / \mathrm{dia}$, de acordo com Food and Agriculture Organization of the United Nations ${ }^{11}$. A distribuição média dos macronutrientes, micronutrientes e das fibras definidas para o presente estudo, indicada para pré-escolares, se encontram resumidos na Tabela 1. 
Tabela 1 - Recomendações diárias de macronutrientes, micronutrientes e fibra para crianças entre 2 e 6 anos de idade

\begin{tabular}{lccc}
\hline $\begin{array}{c}\text { Macronutrientes, } \\
\text { micronutrientes e fibra }\end{array}$ & \% do VCT* & $\begin{array}{c}\text { Valores diários } \\
\text { Quantidade } \\
(\mathrm{g})\end{array}$ & $\begin{array}{c}\text { Energia } \\
(\mathrm{kcal})\end{array}$ \\
\hline Carboidrato & 55,0 & 178,7 & 715 \\
Proteína & 10,0 & 32,5 & 130 \\
Gorduras totais & 35,0 & 50,5 & 455 \\
Gorduras saturadas & 10,0 & 16,85 & 152 \\
Sódio & - & 1,1 & - \\
Fibra & - & 22,0 & - \\
\hline
\end{tabular}

*VCT = Valor calórico total (para esse estudo, 1300 kcal)

Fonte: Adaptado do Institute of Medicine (2005)

\section{Análises estatísticas}

Os dados coletados foram transferidos diretamente para o banco de dados construído no programa Microsoft Office Excel ${ }^{\circ}$. Cada biscoito recheado foi codificado com a letra $\mathrm{M}$ acrescida por um número e inserido no banco de dados.

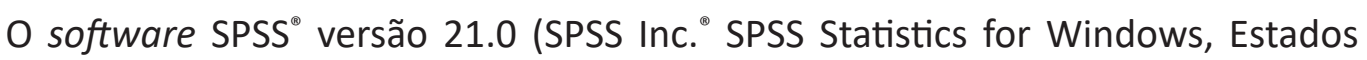
Unidos da América) foi utilizado para a análise estatística, admitindo-se nível de significância de $5 \%(p<0,05)$.

Os valores de energia, carboidrato, proteína, gorduras totais e saturada, sódio e fibra foram descritos por meio dos valores da mediana, mínimo, máximo e intervalo interquartil.

O excesso de carboidrato, proteína, gorduras totais e saturada, sódio e fibra foram calculados por diferença entre os valores observados na rotulagem nutricional e os valores médios de recomendação de nutrientes para a faixa etária de 2 a 6 anos de idade ${ }^{10}$.

As relações entre a conformidade das porções com a legislação brasileira e os valores médios de cada um dos nutrientes declarados por porção entre adultos e crianças foram efetuadas por meio do teste de Wilcoxon. Optou-se por esse teste pelas variáveis não apresentarem distribuição simétrica, verificado por meio do teste Kolmogorov-Smirnov.

\section{RESULTADOS}

Foram observadas a comercialização de 24 tipos de biscoitos recheados nos supermercados visitados nas três principais redes do município. Dentre esses, elegeuse amostra de 16 produtos destinados ao público infanto-juvenil de marcas distintas, 
produzidas por nove empresas do ramo alimentício. Tais amostras foram selecionadas segundo os critérios de inclusão pré-estabelecidos.

Analisando qualitativamente as informações nutricionais declaradas nos rótulos dos produtos, constatou-se que $100 \%$ da amostra $(n=16)$ atendeu aos itens obrigatórios preconizados pela legislação vigente, apresentando as indicações de porção em grama, medida caseira, \%VDR e valor energético de carboidrato, proteína, gordura total, gordura saturada e gordura trans, bem como os conteúdos de fibra alimentar e sódio. Ademais, verificou-se a presença da frase "\% Valores Diários com base em uma dieta de $2.000 \mathrm{kcal}$ ou 8400 kJ. Seus valores diários podem ser maiores ou menores dependendo de suas necessidades energéticas" e da lista de ingredientes.

As análises quantitativas, os valores de mediana, mínimo, máximo e intervalo interquartil de energia, carboidrato, proteína, gorduras totais e saturada, sódio e fibra encontram-se detalhados na tabela 2.

Tabela 2 - Caracterização dos valores de energia, carboidrato, proteína, gorduras totais, gorduras saturadas, sódio e fibra por porção dos biscoitos recheados

\begin{tabular}{lcccc}
\hline & Mínimo & Mediana & Máximo & $\begin{array}{c}\text { Intervalo } \\
\text { interquartil }\end{array}$ \\
\hline Calorias (kcal) & 98,0 & 138,0 & 149,0 & $135,25-142,75$ \\
Carboidrato (g) & 17,0 & 20,5 & 22,0 & $19,25-21,0$ \\
Proteína (g) & 1,3 & 2,0 & 2,4 & $1,7-2,28$ \\
Gorduras totais (g) & 2,9 & 5,3 & 7,1 & $4,63-5,73$ \\
Gorduras saturadas & 1,2 & 2,25 & 3,4 & $1,5-2,98$ \\
(g) & 40,0 & 62,5 & 87,0 & $52,25-70,0$ \\
Sódio (mg) & 0 & 0,7 & 1,2 & $0,53-0,98$ \\
Fibra (g) & & & &
\end{tabular}

Fonte: elaborado pela autora

Observou-se que $100 \%$ das amostras $(n=16)$ apresentaram tamanho de porção adequado ao recomendado pela resolução em vigor ${ }^{8,9}$.

Quanto à categorização em um dos oito grupos identificados pela regulamentação brasileira e do Mercosul, foi constatado que os biscoitos se encontram classificados no grupo dos produtos de panificação, cereais, leguminosas, raízes e tubérculos, e seus derivados, no qual a porção deve fornecer 150 kcal. Entretanto, de acordo com a classificação estabelecida pela resolução RDC $359 / 2003^{9}$, os biscoitos recheados são considerados como pertencentes ao grupo "Açúcares e produtos com energia proveniente de carboidratos e gorduras" e vistos como produtos de consumo ocasional. A legislação estabelece para esses produtos uma porção que deve corresponder a um valor calórico de $100 \mathrm{kcal}$, com uma tolerância média de $\pm 20 \%$. Desse modo, os biscoitos estão classificados erroneamente quanto à categorização e se for respeitado esse valor 
calórico da porção, mesmo com os limites de tolerância, encontramos $93,8 \%$ ( $n=15)$ dos rótulos das marcas analisadas com valor calórico, em média, 15,26 $\pm 5,81 \%$ superior ao recomendado por porção (Tabela 3).

Tabela 3 - Tamanho da porção e o \% de excesso do valor energético declarado no rótulo dos biscoitos recheados analisados classificados no grupo de "Açúcares e produtos com energia proveniente de carboidratos e gorduras"

\begin{tabular}{lcccc}
\hline Marca & Porção & $\begin{array}{c}\text { VE } \\
\text { (kcal) }\end{array}$ & $\begin{array}{c}\text { Excesso } \\
\text { (kcal) }\end{array}$ & $\begin{array}{c}\text { Excesso } \\
\text { (\%) }\end{array}$ \\
\hline M1 & 30g (3unidades) & 145 & 25 & 20,8 \\
M2 & 30g (2unidades) & 98 & Aceitável & Aceitável \\
M3 & 30g (3unidades) & 137 & 17 & 14,2 \\
M4 & 30g (4unidades) & 142 & 22 & 18,3 \\
M5 & 30g (4 1/2 unidades) & 149 & 29 & 24,2 \\
M6 & 30g (3unidades) & 143 & 23 & 19,2 \\
M7 & 30g (3unidades) & 138 & 18 & 15,0 \\
M8 & 30g (3unidades) & 138 & 18 & 15,0 \\
M9 & $30 g$ (3unidades) & 138 & 18 & 15,0 \\
M10 & $30 g$ (3unidades) & 131 & 11 & 9,2 \\
M11 & 30g (4unidades) & 148 & 28 & 23,3 \\
M12 & 30g (3unidades) & 136 & 16 & 13,3 \\
M13 & 30g (3unidades) & 133 & 13 & 10,8 \\
M14 & $30 g$ (3unidades) & 140 & 20 & 16,7 \\
M15 & 30g (2 unidades) & 135 & 15 & 12,5 \\
M16 & 30g (3unidades) & 140 & 20 & 16,7 \\
Média & & $136,94 \pm 11,52$ & $18,31 \pm 6,97$ & $15,26 \pm 5,81$ \\
\hline
\end{tabular}

Nota: VE: Valor Energético

Fonte: elaborado pela autora

Além disso, o valor calórico e demais nutrientes utilizados para calcular o \%VDR de cada porção em todas as marcas analisadas foi baseada em uma necessidade energética recomendada para adultos - $2000 \mathrm{kcal}$ ou $8400 \mathrm{~kJ}$ - diferindo notoriamente da ingestão diária recomendada para crianças com faixa etária de 2 a 6 anos de idade.

Em relação aos macronutrientes, notou-se que todas as marcas analisadas ultrapassaram o \%VDR para crianças, excedendo cerca de 4,69 \pm 0,48\% para carboidratos, $3,46 \pm 0,62 \%$ para proteínas, 0,71 \pm 0,49\% para gorduras totais e 5,12 $\pm 2,1 \%$ para gorduras saturadas (Tabela 4). Dos rótulos analisados, todos declararam não conter a gordura trans.

As informações a respeito do sódio contido nos rótulos de todos os produtos também apresentaram alterações em relação ao determinado para a população infantil, extrapolando 2,9 $\pm 0,66 \%$ a recomendação (Tabela 4), em relação às fibras alimentares 
a variação foi pequena, porém significativa $(0,29 \pm 0,45 \%) \cdot 12,5 \%(n=2)$ dos rótulos analisados declararam não conter esse nutriente (Tabela 4).

Tabela 4 - Comparação do percentual de valor diário declarado nos rótulos em relação ao recomendado pela IDR (IOM, 2005) para crianças de 2 a 6 anos de idade

\begin{tabular}{lcccc}
\hline & $\begin{array}{c}\text { \%VDR Adulto } \\
\text { (\%) }\end{array}$ & $\begin{array}{c}\text { \%VDR Criança } \\
\text { (\%) }\end{array}$ & $\begin{array}{c}\text { Excesso } \\
\text { (\%) }\end{array}$ & p* \\
\hline Carboidratos & $6,75 \pm 0,45$ & $11,44 \pm 0,63$ & $4,69 \pm 0,48$ & $<0,001$ \\
Proteínas & $2,56 \pm 0,51$ & $6,02 \pm 1,01$ & $3,46 \pm 0,62$ & $<0,001$ \\
Gorduras totais & $9,69 \pm 1,82$ & $10,4 \pm 1,99$ & $0,71 \pm 0,49$ & $<0,001$ \\
Gorduras & $10,25 \pm 3,36$ & $15,37 \pm 5,32$ & $5,12 \pm 2,1$ & $<0,001$ \\
saturadas & $2,69 \pm 0,7$ & $5,59 \pm 1,2$ & $2,9 \pm 0,66$ & $<0,001$ \\
Sódio & $2,75 \pm 1,44$ & $3,04 \pm 1,62$ & $0,29 \pm 0,45$ & 0,01 \\
\hline Fibras & & & & \\
\hline
\end{tabular}

* Teste de Wilcoxon

Nota: \% VDR: percentual de valor diário recomendado

Fonte: elaborado pela autora

\section{DISCUSSÃO}

A RDC 359/2003 considera ser direito do consumidor obter as informações nutricionais dos produtos que adquirirem, bem como de conhecer o tamanho da porção adequada ao seu consumo e esclarece que porção "é a quantidade média do alimento que deveria ser consumida por pessoas sadias, maiores de 36 meses de idade em cada ocasião de consumo, com a finalidade de promover uma alimentação saudável" (p.1). Ademais, a porção deve ser indicada em medida caseira de forma a facilitar a compreensão na hora da compra ${ }^{8,9}$.

Todas as amostras analisadas no estudo atenderam ao tamanho da porção recomendada pela RDC $359 / 2003^{9}$, se considerarmos os biscoitos recheados incluídos no grupo "Açúcares e produtos com energia proveniente de carboidratos e gorduras" e de consumo ocasional, indicando uma porção de $30 \mathrm{~g}$. Apesar de todas as amostras analisadas terem atendido as recomendações, Kliemann et al. ${ }^{12}$, encontraram variações nos tamanhos das porções em diversos alimentos industrializados similares. Tal variação é permitida pela legislação, o que favorece a falta de padronização, gerando rótulos confusos e comprometendo a comparação entre diferentes produtos, com influência direta sobre as escolhas alimentares da população.

Tendo em consideração o valor calórico declarado por porção, mesmo com os limites de tolerância respeitados, observou-se que 93,8\% dos rótulos apresentaram, em média, valor calórico $16 \%$ superior ao recomendado pela resolução. Sabe-se que a quantidade de calorias dos biscoitos recheados pode chegar a cinco calorias por grama de produto ${ }^{7}$. 
Isso se agrava quando averiguamos que essa porção é baseada em uma alimentação para adultos, com valor energético diário de $2000 \mathrm{kcal}^{9}$. No entanto, por ser um produto destinado ao público infantil, que apresenta necessidade energética menor, esse tamanho de porção torna-se excessivo tanto em calorias, quanto em carboidratos, proteínas, gorduras e sódio.

O excesso de calorias provenientes, principalmente de tais produtos, tem contribuído para a tendência crescente da prevalência de sobrepeso e obesidade em crianças ${ }^{13}$. No Brasil, o excesso ponderal em jovens praticamente triplicou nos últimos anos $^{1}$, apresentando taxas elevadas tanto para crianças quanto para adolescentes, em todos os grupos de renda e em todas as regiões do país ${ }^{3}$.

Além do excedente em valor calórico, a quantidade de carboidratos encontrada por porção de biscoito das marcas analisadas foi igualmente excessiva, assim como os valores de gordura - total e saturada - e sódio. Em relação aos níveis elevados de sódio, outros estudos também demonstraram valores excessivos. Kraemer et al. ${ }^{14}$, constataram que a maioria dos produtos analisados continham alto ou médio teor de sódio.

Lobanco et al. ${ }^{6}$ observaram inconformidades em mais da metade (52\%) das amostras de biscoitos recheados analisados quimicamente, encontrando quantidade de gordura saturada maior que a especificada na rotulagem nutricional, ultrapassando a variabilidade de $20 \%$ tolerada pela resolução RDC $360 / 2003^{8}$.

O consumo exagerado de gordura, especialmente as saturadas, contribui para a morbimortalidade por doenças cardiovasculares, a longo prazo ${ }^{15}$ e a curto prazo, altera o perfil de lipoproteínas em crianças, com aumento das concentrações do colesterol total e da fração $L^{2} L^{16}$. Além disso, a qualidade dos ingredientes utilizados, como os óleos, açúcares e amidos são questionáveis, visto que na maioria são ingredientes baratos para que tais produtos sejam altamente lucrativos para a indústria de alimentos ${ }^{17}$.

É importante ressaltar que, apesar de não serem mencionados os valores de gordura trans na embalagem dos biscoitos recheados, isso não significa sua inexistência. A regulamentação RDC $360 / 2003^{8}$ permite que os nutrientes que apresentam quantidades não significativas por porção possam ser expressos no rótulo por "zero" ou "não contém"9,12. No caso da gordura trans, valores inferiores a 0,2 g são considerados não significativos e podem ser omitidos da rotulagem; entretanto, se uma quantidade de produto maior que uma porção for consumida, é possível que esse valor se torne expressivo ${ }^{18,19}$. Sendo assim, a ausência de gordura trans no rótulo nutricional não evidencia uma segurança no consumo, devendo o consumidor conferir a lista de ingredientes para descartar a presença de gordura vegetal parcialmente hidrogenada ou seus sinônimos ${ }^{20}$. Kliemann et al. ${ }^{21}$ observaram que $40 \%$ dos produtos analisados se constituíam como falsos negativos, uma vez que alegavam não conter gordura trans, mas exibiam algum componente na lista de ingredientes contendo tal substância. 
A ingestão de alimentos com alto teor de ácidos graxos trans tem se mostrado alto entre as crianças. Um estudo identificou um consumo diário de pelo menos um desses alimentos em 41,4\% das crianças avaliadas, ultrapassando a recomendação diária para a população infantil ${ }^{22}$. A utilização de porções menores no rótulo favorece o destaque de características nutricionais que tendem a agradar ao consumidor, como o caso da gordura trans, podendo ser compreendida pelo consumidor como algo favorável ao consumo ${ }^{12}$.

Além do perfil nutricional desfavorável, o tamanho das embalagens favorece a ingestão de um número maior de biscoitos que o especificado na porção, contribuindo ainda mais no consumo excessivo de calorias, gorduras, açúcares e sódio. Observase que a quantidade de biscoitos correspondente a porção é equivalente a 2 ou 4, quantia inferior à que usualmente é consumida pelos jovens. A população brasileira apresenta um consumo de quantidades superiores as declaradas no rótulo nutricional, levando a uma ingestão excessiva de diversos nutrientes. Kraemer et al. ${ }^{21}$ constataram que o tamanho da porção consumida pelos brasileiros foi até 9,2 vezes superior ao indicado na rotulagem ${ }^{21}$.

Em estudo sobre consumo alimentar de crianças com idades entre 2 e 10 anos, residentes da região Sul do Brasil, observou-se contribuição expressiva dos alimentos ultraprocessados na quantidade de gordura total, gordura trans, carboidratos e sódio da dieta, verificando que o consumo de tais alimentos aumenta proporcionalmente em função da idade da criança - de forma positiva - e em função da escolaridade materna - de forma negativa ${ }^{24}$.

A OMS recomenda que os governos atualizem periodicamente as diretrizes relacionadas a alimentação e nutrição, em função das mudanças nos hábitos alimentares, condições de saúde e progressão do conhecimento científico ${ }^{7}$. Sendo assim, entende-se que o tamanho das porções de produtos ultraprocessados, especialmente os biscoitos recheados destinados ao público infantil, deva ser revista pelos órgãos competentes. Sugere-se que o tamanho das porções de tais produtos considere as necessidades energéticas e de nutrientes do público infanto-juvenil, inclusive com diferenciação por faixas etárias.

Além disso, é importante padronizar as informações sobre a porção e revisar os valores em gramas definidos pela legislação brasileira ${ }^{18}$. O tamanho adequado das porções e a melhor compreensão da rotulagem nutricional tornamse importantes para a tomada consciente de decisão e, consequentemente, para a saúde do consumidor.

Observa-se que a maioria dos consumidores, apesar de considerar as informações contidas nos rótulos nutricionais relevantes, não as compreende adequadamente, por exigirem habilidade para interpretá-las e compreendê-las ${ }^{25,26}$. A Associação Brasileira de 
Saúde Coletiva - $A B R A S C{ }^{27}$, por meio de nota, ressalta que a melhoria da rotulagem dos alimentos, com a inclusão de símbolos que resumam a informação nutricional é uma das ações e estratégias a serem implementadas para o enfrentamento da obesidade. Destaca, ainda, a responsabilidade do governo e seu papel regulador das práticas do setor privado contrárias à saúde da população.

A rotulagem de alimentos é uma das estratégias nutricionais com melhor relação custo-benefício na redução do excesso de peso ${ }^{28,29}$. O Chile implementou um sistema de rotulagem baseado em símbolos que informam visualmente ao consumidor que os alimentos excederam os níveis de energia, açúcar, sódio ou ácidos graxos saturados estipulados. A venda de tais produtos é proibida nas escolas e sua publicidade é restrita, visto que se tem conhecimento de que o marketing de alimentos realça aqueles de menor valor nutricional, voltados principalmente ao público infanto-juvenil ${ }^{29}$.

Destacam-se algumas limitações do estudo, tais como não avaliar quimicamente os biscoitos recheados, utilizando para análise somente os rótulos nutricionais. Entretanto, as informações analisadas no trabalho são aquelas a que os consumidores têm acesso e utilizam para suas escolhas alimentares. Ademais, evidenciou-se a necessidade de melhorias na legislação que determina a rotulagem nutricional e sua fiscalização.

\section{CONCLUSÃO}

Os rótulos nutricionais analisados apresentaram-se adequados qualitativamente, contudo, foram observadas algumas alterações quantitativas, como valores recomendados de calorias, carboidratos e gorduras total e saturada excessivos.

O consumo de tais produtos alimentícios, de composição desbalanceada, tem contribuído para a prevalência de obesidade e suas comorbidades entre os jovens. Portanto, investir em estratégias de educação alimentar e nutricional, especialmente nas escolas e dedicadas ao público infanto-juvenil, é essencial para a mudança do panorama de excesso ponderal observado no Brasil atualmente.

Embora a leitura dos rótulos seja considerada como uma ferramenta essencial para a promoção da saúde e da alimentação saudável, conforme os preceitos e diretrizes da Política Nacional de Alimentação e Nutrição, observa-se que na prática a maioria dos consumidores não compreende tal informação.

Reiteramos a necessidade de mudanças na regulamentação da rotulagem nutricional, incluindo, dentre outras medidas, a colocação dos valores de gorduras trans e a retirada do marketing direcionado ao público infantil, em relação ao melhor esclarecimento da população, uma vez que os rótulos são instrumentos extremamente importantes de educação alimentar e nutricional e de orientação dos consumidores. 


\section{REFERÊNCIAS}

1. Ng M, et al. Global, regional, and national prevalence of overweight and obesity in children and adults during 1980-2013: a systematic analysis for the Global Burden of Disease Study 2013. Lancet. 2014; 384(9945):766-81.

2. Rodrigues VM, Rayner M, Fernandes, AC, Oliveira RC, Proença RPC, Fiates GMR. Comparison of the nutritional content of products, with and without nutrient claims, targeted at children in Brazil. Br J Nutr. 2016; 115: 2047-56.

3. Brasil. Instituto Brasileiro de Geografia e Estatística. Pesquisa de Orçamentos Familiares 2008-2009: antropometria e estado nutricional de crianças, adolescentes e adultos no Brasil. Rio de Janeiro: IBGE; 2010.

4. Brasil. Instituto Brasileiro de Geografia e Estatística. Coordenação de População e Indicadores Sociais. Rio de Janeiro: IBGE; 2016.

5. Marins BR, Araujo IS, Jacob SC. A propaganda de alimentos: orientação, ou apenas estímulo ao consumo?. Ciênc saude colet. 2011; 16(9):3873-82.

6. Lobanco CM, Vedovato GM, Cano, CB, Bastos DHM. Reliability of food labels from products marketed in the city of São Paulo, Southeastern Brazil. Rev Saúde Públ. 2009; 43(3):499-505.

7. Brasil. Ministério da Saúde. Secretaria de Atenção à Saúde. Guia alimentar para a população brasileira. 2ª ed. Brasília; 2014.

8. Brasil. Ministério da Saúde. Agência Nacional de Vigilância Sanitária. Resolução RDC no 359, de 23 de dezembro de 2003: aprova regulamento técnico de porções de alimentos embalados para fins de rotulagem nutricional. Diário Oficial da República Federativa do Brasil, Poder Executivo, Brasília, DF, 26 dez. 2003.

9. Brasil. Ministério da Saúde. Agência Nacional de Vigilância Sanitária. Resolução RDC no 360, de 23 de dezembro de 2003: aprova regulamento técnico sobre rotulagem nutricional de alimentos embalados, tornando obrigatória a rotulagem nutricional. Diário Oficial da República Federativa do Brasil, Poder Executivo, Brasília, DF, 2003 dez 26.

10. Institute of Medicine. Dietary reference intakes for energy, carbohydrate, fiber, fat, fatty acids, cholesterol, protein, and amino acids. Washington (DC): National Academy Press; 2005.

11. Food and Agriculture Organization of the United Nations. Human energy requirements. Report of a Joint FAO/WHO/UNU Expert Consultation, Rome, 2004.

12. Kliemann N, Veiros NB, González-Chica DA, Proença RPC. Serving size on nutrition labeling for processed foods sold in Brazil: Relationship to energy value. Rev. Nutr. 2016; 29(5):741-50.

13. Correa SF, Vencato PH, Rockett FC, Bosa VL. Dietary patterns: are there differences 
between children and adolescents? Cienc saude colet. 2017; 22(2):553-62.

14. Kraemer MVS, Oliveira RC, González-Chica DA, Proença RPC. Sodium content on processed foods for snacks. Public Health Nutr. 2016; 19(6):967-75.

15. Xavier HT, Izar MC, Faria Neto JR, Assad MH, Rocha VZ, Sposito AC, et al. Diretriz Brasileira de Dislipidemias e Prevenção da Aterosclerose. Arq Bras Cardiol. 2013; 101(4).

16. Rauber F, Campagnolo PDB, Hoffman DJ, Vitolo MR. Consumption of ultraprocessed food products and its effects on children's lipid profiles: A longitudinal study. Nutr Metab Cardiovasc Dis. 2015; 25(1):116-22.

17. Louzada MLC, Martins APB, Canella DS, Baraldi LB, Levy RB, Claro RM, Moubarac JC, Cannon G, Monteiro CA. Ultra-processed foods and the nutritional dietary profile in Brazil. Rev Saúde Públ; 2019,49(38).

18. Kliemann N, Veiros MB, González-Chica DA, Proença RPC. Reference serving sizes for the Brazilian population: An analysis of processed food labels. Rev Nutr. 2014; 27(3):329-41.

19. Longo-Silva G, Toloni MHA, Menezes RCE, Asakura L, Oliveira MAA, Taddei JAAC. Ultra-processed foods: Consumption among children at day-care centers and their classification according to Traffic Light Labelling system. Rev Nutr. 2015; 28(5):54353.

20. Proença RPC, Silveira BM. Intake recommendations and labeling of trans fat in processed foods in Brazil: analysis of official documents. Rev Saúde Públ. 2012; 46(5):923-8.

21. Dias JR, Gonçalves ECBA. Avaliação do consumo e análise da rotulagem nutricional de alimentos com alto teor de ácidos graxos trans. Ciênc Tecnol Aliment. 2009; 29(1):177-82.

22. Kliemann N, Kraemer M, Silveira BM, González-Chica DA, Proença RPC. Tamanho da porção e gordura trans: os rótulos de alimentos industrializados brasileiros estão adequados? Demetra. 2015; 10(1):43-60.

23. Kraemer MVS, Machado PP, Kliemann N, González-Chica DA, Proença RPC. The Brazilian population consumes larger serving sizes than those informed on labels. British Food Journal. 2015; 117(2),719-30

24. Sparrenberger K, Friedricha RR, Schiffnerb MD, Schuchc I, Wagner MB. Ultraprocessed food consumption in children from a Basic Health Unit. Pediatr. 2015; 91:535-42.

25. Pontes TE, Costa TF, Marum ABRF, Brasil ALD, Taddei JAAC. Orientação nutricional de crianças e adolescentes e os novos padrões de consumo: propagandas, embalagens e rótulos. Rev Paul Pediatr. 2009; 27(1):99-105.

26. Graham DJ, Lucas-Thompson RG, Mueller MP, Jaeb M, Harnack L. Impact of 
explained v. unexplained front-of-package nutrition labels on parent and child food choices: a randomized trial. Public Health Nutr. 2017; 20(5):774-85.

27. Associação Brasileira de Saúde Coletiva. Nota Abrasco "Para enfrentar a obesidade é necessário fazer muito mais que descascar alimentos in natura". Rio de Janeiro: Associação Brasileira de Saúde Coletiva [Internet]. 2017 [acesso em 2018 abr 17]. Disponível em: https://www.abrasco.org.br/site/noticias/institucional/notaabrasco-para-enfrentar-a-obesidade-e-necessario-fazer-muito-mais-que-descascaralimentos-in-natura/27604/.

28. Cecchini M, Sassi F, Lauer JA, Lee YY, Guajardo-Barron V, Chisholm D. Tackling of unhealthy diets, physical inactivity, and obesity: health effects and costeffectiveness. Lancet. 2010; 20;376(9754):1775-84.

29. Rodríguez Osiac L, Cofré C, Pizarro T, Mansilla C, Herrera CA, Burrows J, et al. Using evidenceinformed policies to tackle overweight and obesity in Chile. Rev Panam Salud Publica. 2017; 41:e156.

Submissão: fevereiro de 2019.

Aprovação: fevereiro de 2020. 